\title{
CLINICAL EVALUATION OF USING BENZYDAMINE HYDROCHLORIDE ORAL GEL WITH INTRALESIONAL CORTICOSTEROID INJECTION FOR PAIN CONTROL IN SYMPTOMATIC ORAL LICHEN PLANUS
}

\author{
Lama H. El-Marssafy*, Hesham S Sadek ${ }^{* *}$, Fatma F Hussein ${ }^{* * *}$, \\ Mashael Alqahtani***** and Wahdan M Abdelghany ${ }^{* * * * * *}$
}

\begin{abstract}
Introduction: Lichen planus is a chronic inflammatory immune-mediated disease affecting skin and mucous membrane. Oral lichen planus (OLP) appears clinically as symmetrically distributed rough white striations on a mild background erythema. Erosive and atrophic lesions characterized by causing sensitive sensation or pain ranging from episodic to severe discomfortable pain. Treatment of OLP is mainly by topical or systemic corticosteroids. Intralesional injection of corticosteroid was used for treatment of extensive or recalcitrant symptomatic OLP lesions. Various types of topical analgesics could be used in accompanied with corticosteroid therapy to decrease pain sensation in a safe way. Benzydamine Hydrochloride is used due to its anesthetic, analgesic, antimicrobial, and anti-inflammatory action as a topical non-steroidal agent.
\end{abstract}

Materials and Methods: Twenty patients participated in this study having symptomatic bullous erosive OLP. In the first group, ten patients treated by intra-lesional corticosteroid injection alone. In the second group ten patients treated with intra-lesional corticosteroid injection accompanied with Benzydamine Hydrochloride oral gel.

Results: A statistical significant difference exists between both groups regarding visual analog scale by the end of first and third week. Also by the end of third and fourth week statistical significant difference exists between both groups in grades of clinical improvement which was in favor of the combination therapy group.

Conclusion: Benzydamine hydrochloride gel is considered a simple, safe, well tolerated and effective method to reduce the severity of symptomatic oral lichen planus.

KEYWORD: Oral lichen planus, intra-lesional corticosteroid, Benzydamine Hydrochloride.

\footnotetext{
* Assistant Professor of Oral Medicine, Oral Diagnosis and Periodontology, Department of Basic and Clinical Oral Sciences, Collage of Dentistry, Umm Al Qura University, KSA.

** Professor, Department of Oral Medicine, Oral Diagnosis and Periodontology, Faculty of Dentistry, Cairo University, Egypt. Affiliated as Professor in Collage of Dentistry, Umm- Al-Qura University, KSA.

*** Lecturer, Department of Oral Medicine, Oral Diagnosis and Periodontology, Faculty of Dentistry, Minia University, Egypt. Affiliated as Assistant Professor in Collage of Dentistry, Umm- Al-Qura University, KSA.

**** Assistant Professor of Oral and Maxillofacial Pathology, Department of Basic and Clinical Oral Sciences, Collage of Dentistry, Umm Al Qura University, KSA.

***** Assistant professor of Dental Public Health and Preventive Dentistry, Department of Pediatric, Faculty of Dentistry, Mansoura University, Egypt. Affiliated as Assistant Professor in Collage of Dentistry, Umm- Al-Qura University, KSA.
} 


\section{INTRODUCTION}

Lichen planus is a chronic inflammatory immune-mediated disease affecting skin and mucous membrane. ${ }^{1}$ The disease affects $1-2 \%$ of the general population showing maximum prevalence in women above the age of $40 .^{2}$ Cutaneous lichen planus tends to be self-limiting, while oral lichen planus which tends to occur more frequently is more resistant to treatment and rarely undergo self-remission. ${ }^{3}$ Oral lichen planus (OLP) appears clinically as symmetrically distributed rough white striations on a mild background erythema, usually affecting buccal mucosa, tongue and the gingiva. ${ }^{4}$ Also it appears with other clinical presentation as popular, atrophic, erosive, bullous and plaque-like lesions. ${ }^{5}$ The erosive and atrophic lesions characterized by causing sensitive sensation or pain ranging from episodic to severe discomfortable pain. ${ }^{6}$

Studies had shown increased risk of malignant transformation in patients having oral lichen planus especially in atrophic or erosive forms. ${ }^{7-9}$ Patients having OLP showed higher risk of developing squamous cell carcinoma nearly ten times more than normal people. ${ }^{10}$ Etiology of lichen planus is not adequately understood. Several hypotheses had described the pathogenesis of the disease as antigenspecific or non specific mechanisms, humoral immunity or autoimmune response. ${ }^{11-15}$

In antigen specific theory, although the lichen planus antigen is unknown it could be a selfpeptide. Both CD8+ cytotoxic T cells and CD4+ helper cells are activated if presented to antigens through MHC II and I respectively. This may be mediated by langerhans cells or kiratinocytes. The activated cytotoxic $\mathrm{T}$ cells secrete TNF- $\alpha$ which triggers basal keratinocytes apoptosis. ${ }^{13,16}$ According to the non-specific hypothesis, part of $\mathrm{T}$ cells are not antigen specific. They are attracted to the lesion by other mechanisms associated with pre-existing inflammation. Chemokines, matrix mettalloproteinases, mast cell degranulation and basement membrane disruption all cause movement of lymphocyte into the epithelium and destruction of keratinocytes. ${ }^{13,17,18}$ Various studies showed increased amount of mast cells degranulation in OLP approximately $60 \%$ compared with $20 \%$ in normal buccal mucosa. ${ }^{19,20}$ This degranulation releases proinflammatory mediators as TNF- $\alpha$, chymase and IL$1 \beta$. TNF- $\alpha$ up-regulate the endothelial cell adhesion molecules expression which facilitate lymphocyteendothelial adhesion and extravasation..$^{21-23}$ At the same time TNF- $\alpha$ stimulate MMP-9 secretion by T-lymphocytes causing disruption of basement membrane and triggering keratinocyte apoptosis. MMP-9 also allows the passage of antigen-specific CD8+ cytotoxic T-cells to the OLP epithelium with further kiratinocyte apoptosis..$^{24-27}$

As a result, decreasing or blocking the inflammatory mediators and cytokines in OLP may have a beneficial therapeutic effect on the disease. ${ }^{28}$ Treatment of OLP is mainly by topical or systemic corticosteroids. ${ }^{29,30}$ Other treatment modalities as cyclosporine, retinoic acid and photochemotherapy are also used. ${ }^{31}$ Intralesional injection of corticosteroid were used for treatment of extensive or recalcitrant symptomatic OLP lesions. ${ }^{32,33}$ Pain accompanied with burning sensation in ulcerative OLP is the main difficulty facing patients with this disease. ${ }^{34}$ Various types of topical analgesics could be used accompanied with corticosteroid therapy to decrease pain sensation in a safe way. Diphenhydramine elixir, xylocaine, lignocaine or benzydamine hydrochloride were used in the form of mouth wash, gel or spray. ${ }^{35,36}$

Benzydamine Hydrochloride (Bnz HCL) is used due to its anesthetic, analgesic, antimicrobial, and anti-inflammatory action as a topical non-steroidal agent. It characterized by alkaline $\mathrm{pH}$ which allows its concentration in the inflamed tissue with minimum systemic absorption. ${ }^{37}$, The present study was conducted to clinically evaluate the effect of adding Benzydamine Hydrochloride oral 
gel accompanied with intralesional corticosteroid injection on pain relief through the management of symptomatic OLP.

\section{MATERIALS AND METHODS}

Twenty patients participated in this study having bullous erosive OLP were selected from outpatient clinic of faculty of Dentistry Umm Ulqurra University. The patients had an average age ranging from 30 to 55 years old. All patients were selected to be medically free according to Cornell Medical Inde ${ }^{38}$. Patients were diagnosed with OLP by means of clinical and histopathological examination. ${ }^{39}$ Exclusion criteria included any patient under 18 years old or had a history of taking any type of corticosteroid or other immunosuppressive therapy through the past 4 weeks or any drug that might produce lichenoid reaction. Pregnant and lactating female were also excluded from this study.The patients participated in this study were provided verbal information on the study protocol and randomly divided into two groups as follows:

\section{I) The first group:}

It consists of ten patients who received intralesional corticosteroid injection alone. The patients were given $40 \mathrm{mg}$ of injectable triamcinolone acetonide (Kenacort-A*: $1 \mathrm{ml}$ triamcinolone acetonide aqueous suspension) which was diluted by $1 \mathrm{ml}$ of anaesthetic solution (Mepivacaine hydrochloride ${ }^{* *} 0.020 \mathrm{~g} / \mathrm{ml}$ and adrenaline base $0.010 \mathrm{mg} / \mathrm{ml}$ ) to help in relieving pain of the injection. The injectable drug was given once weekly with a maximum dose of three injections.

\section{II) The second group:}

It consists of ten patients who received intralesional corticosteroid injection accompanied with
Benzydamine Hydrochloride oral gel. The patients were given $40 \mathrm{mg}$ of injectable triamcinolone acetonide (Kenacort-A: $1 \mathrm{ml}$ triamcinolone acetonide aqueous suspension) which was diluted by $1 \mathrm{ml}$ of anaesthetic solution (Mepivacaine hydrochloride $0.020 \mathrm{~g} / \mathrm{ml}$ and adrenaline base $0.010 \mathrm{mg} / \mathrm{ml}$ ) to help in relieving pain of the injection.

The injectable drug was given once weekly with a maximum dose of three injections. At the same time the patients will apply topical application of (Difflam* 10g mouth gel, each $\mathrm{g}$ contains: Benzydamine hydrochloride 10mg, Cetylpyridinium chloride $1 \mathrm{mg}$ ) four times per day at the affected buccal mucosa (half an hour before meal $\&$ before bed time). Patients were asked to apply $1 \mathrm{~cm}$ of the gel with finger and gently massage into the affected area and prevent to eat or drink for 30 minutes after each application.

\section{Evaluation of parameters:}

Evaluation of parameters for this study was done by two items:

First: the visual analog scale VAS: ${ }^{40}$

Pain intensity was evaluated weekly by 10-point Visual Analog Scale (VAS) for four weeks as follows: It is a horizontal line $10 \mathrm{~cm}$ in length and was classified as follows. Score $0-1 \mathrm{~cm}$ - no pain or distress, score 2-3 cm- annoying, score 4-5 $\mathrm{cm}$ - uncomfortable, score 6-7 cm- dreadful, score 8-9 cm- horrible and score $10 \mathrm{~cm}$ - agonizing or unbearable distress.

Second: the clinical improvement was assessed weekly for four weeks as follows: ${ }^{41}$

Grade 0: No improvement.

Grade I: Minimal improvement \{mild subjective relief \& small reduction in the lesion size $\}$.

\footnotetext{
* KenacortTM-A I.M.: Bristol-Myers Squibb; Anagni (FR)- Italy

** Mepecaine hydrochloride: Septodont- France

*** Difflam Mouth Gel, Inova Pharmaceuticals, Australia.
} 
Grade II: Moderate improvement \{obvious subjective relief \& moderate resolution in the lesion size\}.

Grade III: Dramatic improvement \{remarkable subjective relief \& most of the lesion disappeared\}.

Grade IV: The patient gets pain free \& complete disappearance of the lesion.

Photographs were taken for OLP lesions at time of clinical examination, one, two, three \& four weeks after beginning of treatment

\section{Statistical analysis:}

The collected data were analyzed using a Statistical Package for the Social Sciences software program (IBM SPSS Statistics for Windows, Version 21.0. Armonk, NY: IBM Corp). Chi square test was used to compare between the two groups at the different follow up intervals and to compare between both visual analog scale and clinical improvement grades at different follow up for each group. The level of significance was considered statistically significant at $\mathrm{p} \leq 0.05$.

\section{RESULTS}

Twenty patients participated in this study (12 males \& 8 females) having symptomatic bullous erosive OLP with age ranging from 30 to 55 years and average age about 42 years. All the patients having disease duration ranged from 6 months to 4 years and all of them were free from any skin lesions.

By the end of first week $10 \%$ of patients in (group I) showed uncomfortable pain, 70\% showed dreadful pain and $20 \%$ with horrible pain. Group II patient's showed 20\% uncomfortable pain, $60 \%$ with dreadful pain and $20 \%$ with horrible pain. After two weeks $10 \%$ of patients in (group I) showed annoying pain, 30\% uncomfortable pain, $50 \%$ dreadful pain and $10 \%$ horrible pain. While (group II) $20 \%$ of patients showed annoying pain, $40 \%$ uncomfortable pain and $40 \%$ dreadful pain.

\section{Pain improvement: Table (1) Graph (1)}

After third week $20 \%$ of (group I) patients showed annoying pain, $40 \%$ uncomfortable pain and $40 \%$ with dreadful pain. Group II showed $20 \%$ with no pain, $30 \%$ with annoying pain, $30 \%$ showed uncomfortable pain and $20 \%$ with dreadful pain. Also by the end of fourth week $10 \%$ of patients in (group I) showed no pain, 20\% with annoying pain, $50 \%$ with uncomfortable pain and $20 \%$ showed dreadful pain. Group II showed $30 \%$ of patients with no pain, $40 \%$ with annoying pain, $20 \%$ with uncomfortable pain and $10 \%$ showed dreadful pain.

A statistical difference between both groups exists after the first and third weeks while after the second and fourth weeks no statistical difference exists between them.

\section{Clinical improvement: Table (2) Graph (2)}

At the end of the first week $40 \%$ of the patients in (group I) showed no improvement, $40 \%$ minimal improvement and 20\% moderate improvement. While in (group II) $20 \%$ of patients showed no improvement, $50 \%$ minimal improvement and $30 \%$ moderate improvement. After two weeks $30 \%$ of patients in (group I) showed no improvement, $30 \%$ minimal improvement and $40 \%$ moderate improvement. Group II $10 \%$ showed no improvement, $40 \%$ with minimal improvement and $50 \%$ with moderate improvement. The difference between both groups by the end of first and second weeks was statistically insignificant.

By the end of third week, $10 \%$ of patients in (group I) showed no improvement, 20\% minimal improvement, $60 \%$ moderate improvement and $10 \%$ dramatic improvement. Group II 10\% showed minimal improvement, $60 \%$ moderate improvement, $20 \%$ dramatic improvement and $10 \%$ were pain free. While by the end of fourth week $20 \%$ of patients in (group I) showed minimal improvement, $70 \%$ moderate improvement and $10 \%$ dramatic improvement. In (group II) $10 \%$ of patients showed 
TABLE (1): comparison between visual analog scale of patients treated with Intra-lesional corticosteroid drug alone (Group I) and corticosteroid drug with $\mathrm{Bnz} \mathrm{HCl}$ gel (Group II):

\begin{tabular}{|c|c|c|c|c|c|c|c|}
\hline \multicolumn{2}{|c|}{ Duration } & $\begin{array}{l}\text { Score I } \\
\text { No }(\%)\end{array}$ & $\begin{array}{l}\text { score II } \\
\text { No }(\%)\end{array}$ & $\begin{array}{l}\text { score III } \\
\text { No }(\%)\end{array}$ & $\begin{array}{l}\text { score IV } \\
\text { No }(\%)\end{array}$ & $\begin{array}{l}\text { Score } \mathrm{V} \\
\text { No }(\%\end{array}$ & $\begin{array}{l}\text { score VI } \\
\text { No }(\%)\end{array}$ \\
\hline \multirow{3}{*}{$\begin{array}{c}\text { After } \\
1^{\text {st }} \text { Week }\end{array}$} & Group I & $0(0 \%)$ & $0(0 \%)$ & $1(10 \%)$ & $7(70 \%)$ & $2(20 \%)$ & $0(0 \%)$ \\
\hline & Group II & $0(0 \%)$ & $0(0 \%)$ & $2(20 \%)$ & $6(60 \%)$ & $2(20 \%)$ & $0(0 \%)$ \\
\hline & $\mathrm{p}$ & \multicolumn{6}{|c|}{$0.006^{*}$} \\
\hline \multirow{3}{*}{$\begin{array}{c}\text { After } \\
2^{\text {nd }} \text { Week }\end{array}$} & Group I & $0(0 \%)$ & $1(10 \%)$ & $3(30 \%)$ & $5(50 \%)$ & $1(10 \%)$ & $0(0 \%)$ \\
\hline & Group II & $0(0 \%)$ & $2(20 \%)$ & $4(40 \%)$ & $4(40 \%)$ & $0(0 \%)$ & $0(0 \%)$ \\
\hline & $\mathrm{p}$ & \multicolumn{6}{|c|}{0.174} \\
\hline \multirow{3}{*}{$\begin{array}{c}\text { After } \\
3^{\text {rd }} \text { Week }\end{array}$} & Group I & $0(0 \%)$ & $2(20 \%)$ & $4(40 \%)$ & $4(40 \%)$ & $0(0 \%)$ & $0(0 \%)$ \\
\hline & Group II & $2(20 \%)$ & $3(30 \%)$ & $3(30 \%)$ & $2(20 \%)$ & $0(0 \%)$ & $0(0 \%)$ \\
\hline & $\mathrm{p}$ & \multicolumn{6}{|c|}{$0.011^{*}$} \\
\hline \multirow{3}{*}{$\begin{array}{c}\text { After } \\
4^{\text {th }} \text { week }\end{array}$} & Group I & $1(10 \%)$ & $2(20 \%)$ & $5(50 \%)$ & $2(20 \%)$ & $0(0 \%)$ & $0(0 \%)$ \\
\hline & Group II & $3(30 \%)$ & $4(40 \%)$ & $2(20 \%)$ & $1(10 \%)$ & $0(0 \%)$ & $0(0 \%)$ \\
\hline & $\mathrm{p}$ & \multicolumn{6}{|c|}{0.057} \\
\hline
\end{tabular}

Score I = Score 0-1 cm- no pain, Score II = score 2-3 cm- annoying, Score III = score 4-5 cm- un comfortable, Score IV = score 6-7 cm-dreadful, Score V = score $8-9 \mathrm{~cm}$ - horrible, Score VI = score $10 \mathrm{~cm}$-agonizing, Group $1=$ patients treated with intra-lesional corticosteroid drug alone, Group 2 = patients treated with intra-lesional corticosteroid drug with Bnz $\mathrm{HCl}$ gel, Similar capital letters = significant difference between the corresponding groups at different durations, No = Number, $\mathrm{p}=$ p value calculated by Chi square test.

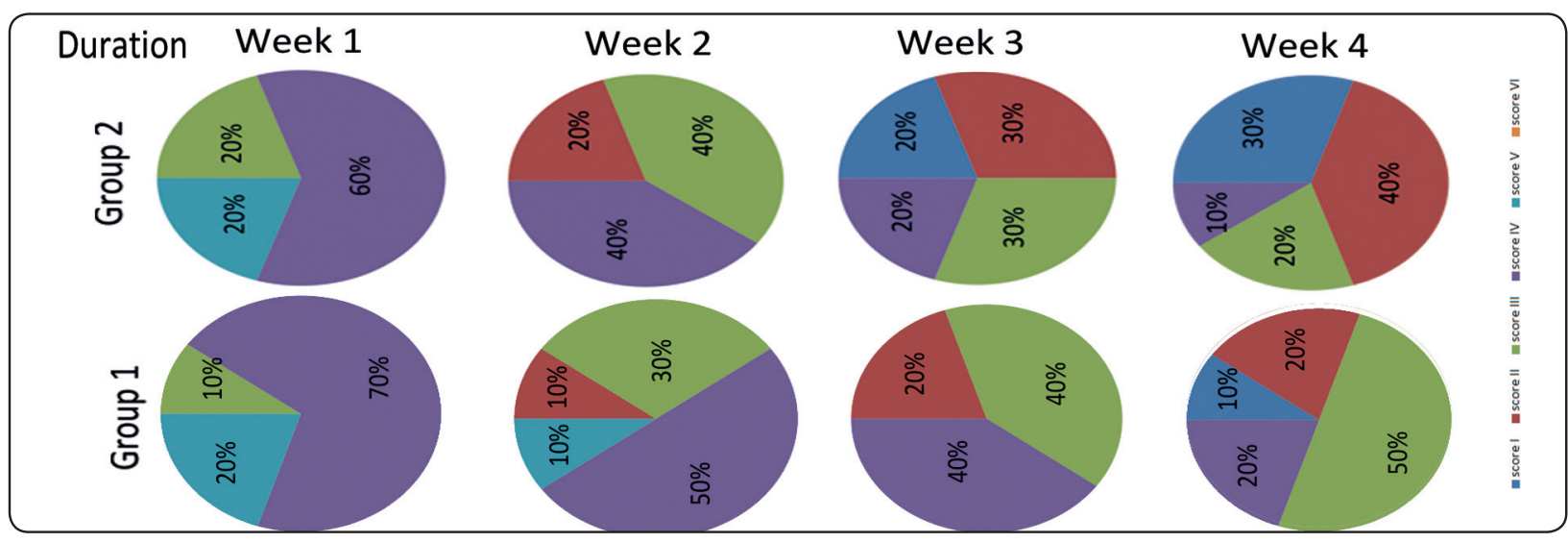

Graph (1): comparison between percentages of visual analog scale of patients treated with intra-lesional corticosteroid drug alone and corticosteroid drug with $\mathrm{Bnz} \mathrm{HCl}$ gel: 
TABLE (2): Comparison between clinical improvement grades of patients treated with intra-lesional corticosteroid drug alone and intra-lesional corticosteroid drug with $\mathrm{Bnz} \mathrm{HCl}$ gel:

\begin{tabular}{|c|c|c|c|c|c|c|}
\hline \multicolumn{2}{|c|}{ Duration } & $\begin{array}{l}\text { Grade } 0 \\
\text { No }(\%)\end{array}$ & $\begin{array}{l}\text { Grade I } \\
\text { No }(\%)\end{array}$ & $\begin{array}{l}\text { Grade II } \\
\text { No }(\%)\end{array}$ & $\begin{array}{l}\text { Grade III } \\
\text { No }(\%)\end{array}$ & $\begin{array}{c}\text { Grade IV } \\
\text { No }(\%)\end{array}$ \\
\hline \multirow{3}{*}{$\begin{array}{c}\text { After } \\
1^{\text {st }} \\
\text { week }\end{array}$} & Group 1 & $4(40 \%)$ & $4(40 \%)$ & $2(20 \%)$ & $0(0 \%)$ & $0(0 \%)$ \\
\hline & Group 2 & $2(20 \%)$ & $5(50 \%)$ & $3(30 \%)$ & $0(0 \%)$ & $0(0 \%)$ \\
\hline & $\mathrm{p}$ & \multicolumn{5}{|c|}{0.061} \\
\hline \multirow{3}{*}{$\begin{array}{c}\text { After } \\
2^{\text {nd }} \\
\text { week }\end{array}$} & Group 1 & $3(30 \%)$ & $3(30 \%)$ & $4(40 \%)$ & $0(0 \%)$ & $0(0 \%)$ \\
\hline & Group 2 & $1(10 \%)$ & $4(40 \%)$ & $5(50 \%)$ & $0(0 \%)$ & $0(0 \%)$ \\
\hline & $\mathrm{p}$ & \multicolumn{5}{|c|}{0.070} \\
\hline \multirow{3}{*}{$\begin{array}{c}\text { After } \\
3^{\text {rd }} \\
\text { week }\end{array}$} & Group 1 & $1(10 \%)$ & $2(20 \%)$ & $6(60 \%)$ & $1(10 \%)$ & $0(0 \%)$ \\
\hline & Group2 & $0(0 \%)$ & $1(10 \%)$ & $6(60 \%)$ & $2(20 \%)$ & $1(10 \%)$ \\
\hline & $\mathrm{p}$ & \multicolumn{5}{|c|}{$0.012^{*}$} \\
\hline \multirow{3}{*}{$\begin{array}{c}\text { After } \\
4^{\text {th }} \\
\text { week }\end{array}$} & Group 1 & $0(0 \%)$ & $2(20 \%)$ & $7(70 \%)$ & $1(10 \%)$ & $0(0 \%)$ \\
\hline & Group 2 & $0(0 \%)$ & $1(10 \%)$ & $5(50 \%)$ & $3(30 \%)$ & $1(10 \%)$ \\
\hline & $\mathrm{p}$ & \multicolumn{5}{|c|}{$0.021^{*}$} \\
\hline
\end{tabular}

Group 1 = patients treated with intra-lesional corticosteroid drug alone, Group 2 = patients treated with intra-lesional corticosteroid drug with $\mathrm{Bnz} \mathrm{HCl}$ gel, Similar capital letters = significant difference between the corresponding groups at different durations, No = Number, $\mathrm{p}=\boldsymbol{p}$ value calculated by Chi square test and considered statistically significant at values $\leq 0.05$.

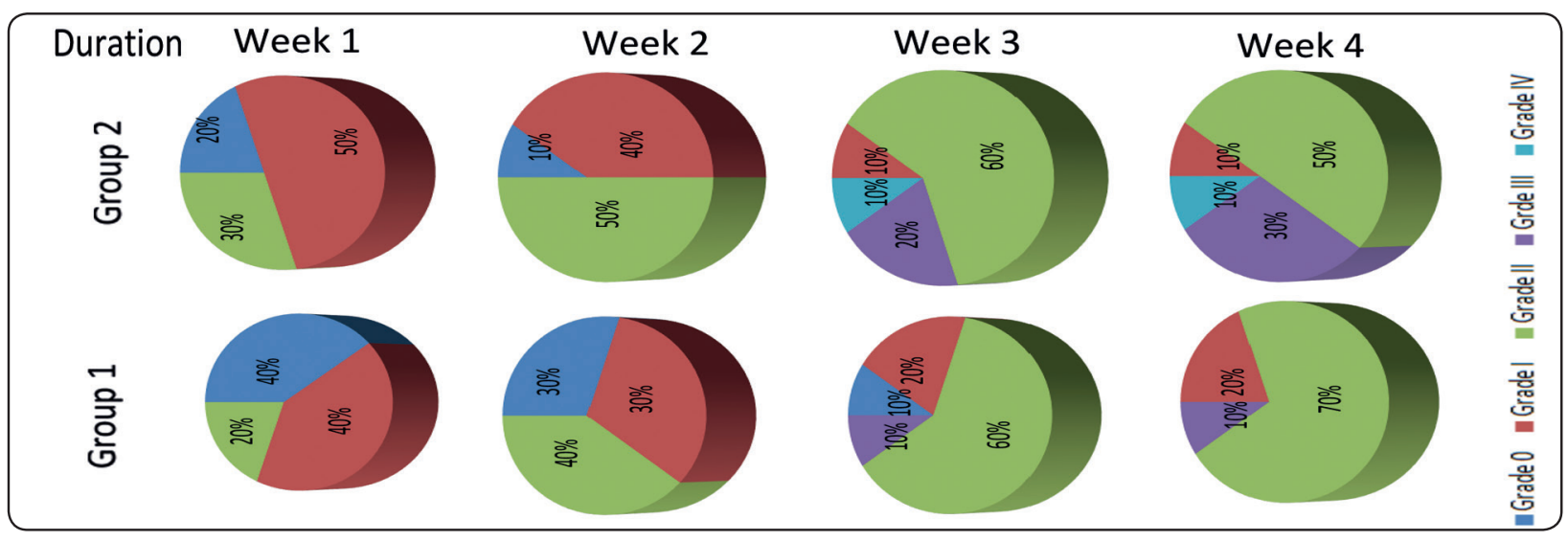

Graph (2): Comparison between percentages of clinical improvement grades of patients treated with intra-lesional corticosteroid drug alone and corticosteroid drug with $\mathrm{Bnz} \mathrm{HCl}$ gel: 
minimal improvement, $50 \%$ moderate improvement, $30 \%$ dramatic improvement and $10 \%$ were pain free. The difference between both groups by the end of third and fourth weeks was statistically significant.

\section{Changes within each group: Table 3}

In the first group intra-lesional corticosteroid drug alone:

A statistically significant difference exists between first and second weeks regarding decrease in pain intensity, while the difference from the second to the fourth weeks was insignificant. While regarding clinical improvement the significant difference exists only between the third and the fourth weeks.

In the second group intra-lesional corticosteroid drug with Bnz HCL gel:

Regarding the decrease in pain intensity the significant difference exists between the first and second weeks and the second and third weeks. On the other hands, clinical improvement was statistically significant between the second and third weeks and by the end of fourth week.

\section{DISCUSSION}

Benzydamine as a tertiary amine have a multiple therapeutic applications due to its anti-inflammatory, analgesic, antipyretic, antimicrobial and anesthetic effects. Mechanism of action exists in its antiTNF alpha effect and membrane stabilization which prevent the release of arachidonic acid cycle and the formation of pro-inflammatory cytokines and prostaglandins. ${ }^{42-45}$ Various studies used Bnz HCL as a prophylaxis in management of radiation-induced mucositis or other ulcerative mucosal conditions with statistically significant beneficial effect of Bnz HCL when compared with placebo. ${ }^{46-48}$ It is used either systemically or topically in the form of spray, gel or mouthwash. ${ }^{49}$ During using Benzydamine Hydrochloride as mouth wash for 30 seconds, a limited amount is absorbed to the buccal mucosa. This was confirmed by the only $5 \%$ systemic availability as peak plasma concentration reached $0.5 \mu \mathrm{mol} / 1^{2}$ only after three hours..$^{50,51}$ At the same time, gel formulations are preferred with topical application for their easily application on mucosal tissues and ability to release the drug molecules at the target site..$^{52}$

TABLE (3): The effect of duration on visual analog scores and clinical improvements grades for each group:

\begin{tabular}{|c|l|c|c|c|}
\hline \multicolumn{2}{|c|}{ Visual analog scale } & W1 vs W2 & W2 vs W3 & W3 vs W4 \\
Duration & $\mathrm{p}$ & $\mathrm{p}$ & 0.115 \\
\hline \multirow{2}{*}{ Group 1 } & Analog scores & $0.021^{*}$ & 0.174 & $0.010^{*}$ \\
\cline { 2 - 5 } & Clinical improvements & 0.057 & 0.081 & 0.137 \\
\hline \multirow{2}{*}{ Group 2 } & Analog scores & $0.010^{*}$ & $0.011^{*}$ & $0.002^{*}$ \\
\cline { 2 - 5 } & Clinical improvements & 0.080 & $0.030^{*}$ & \multirow{2}{*}{} \\
\hline
\end{tabular}

$\mathbf{W}=$ Week, $\mathbf{p}=$ p value calculated by Chi square test, ${ }^{*}=$ statistically significant. 
This study was done to evaluate the effect of adding Benzydamine Hydrochloride oral gel accompanied with intralesional corticosteroid injection on pain relief for patients having Bulous erosive lichen planus. All selected patients were medically free according to Cornell Medical Index ${ }^{38}$ Moreover, they did not receive any medication that might produce lichenoid reaction or influence the judgment of drug effectiveness used in this study. Diagnosis of oral lichen planus was confirmed by clinical and histopathological examinations. Through the study, patients sustain variable sensation by the use of topical benzydamine hydrochloride gel as numbness or tingling in the tissues, dryness or nausea especially when the gel was applied at the backward area of the buccal mucosa.

The most important complaint for patient having bullous erosive lichen planus is the pain or the burning sensation. For that we choose the VAS scores as an index for the improvement of the condition. At the end of the first week there was a statistically significant difference between the intralesion steroid group and the the Bnz-HCL + intralesion steroid group regarding pain sensation while a non significant difference exists between both groups regarding clinical improvement. This might be due to the topical analgesic effect of Bnz-HCL on the tissues through membrane stabilization and inhibition of prostaglandin formation. The partial analgesic effect of Bnz-HCL remains for 1.84 hours. In our study patient were topically applying Bnz-HCL gel four times per day at the affected buccal mucosa (half an hour before meal $\&$ before bed time). This allows the effect of the gel to stay approximately for 8 hours per day. Topical anesthetics as benzocaine and lidocaine could be locally applied at the sites of painful ulcers. However, the duration of analgesic effect of lidocaine as spray on the oral mucosa is only $15 \mathrm{~min}$. Beside that there is an increased risk of aspiration or systemic absorption that might affect the heart..$^{53,54}$
By the end of second week a non significant difference exists between both groups regarding pain sensation or grades of clinical improvement. However, by the end of third week a significant difference exists between both groups in these two parameters. The significant difference between both groups continues to exist by the end of fourth week in the grades of clinical improvement. First group taking intra-lesion steroid only showed $20 \%$ of patients with minimal improvement, $70 \%$ with moderate improvement and $10 \%$ with dramatic improvement. While the second group taking intralesion steroid+ Bnz-HCL gel showed better clinical improvement with $10 \%$ of patients having minimal improvement, $50 \%$ having moderate improvement and $30 \%$ having dramatic improvement and $10 \%$ of patients showed pain free and disappearance of the lesion.

A statistically significant difference in pain sensation and grades of clinical improvement occurs within each group through the treatment period. This statistical difference occurs in pain scores between the first and second weeks and the second and third weeks in the second group (intra-lesion steroid+ Bnz-HCL gel). Regarding clinical improvement in this group the statistical difference exists between the second and third weeks and the third and fourth weeks. These statistical improvements in pain scores and clinical improvement are due to the combined anti-inflammatory effects of intra-lesion steroid with Bnz-HCL gel. On the other hand the statistical significant difference in pain scores occurs at the first group (intra-lesion steroid alone) in the second week only and the statistical difference in clinical improvement occurs just between the third and fourth weeks.

The combination therapy of intra-lesion steroid with Bnz-HCL gel lead to reduction in influx of inflammatory cells into the affected tissues, decrease pain sensation and improve healing of the affected lesion. ${ }^{48,55}$ 
In 2009 Karavana et al, ${ }^{56}$ examined the application of benzydamine hydrochloride gel on oral ulceration exists at buccal bovine mucosa which showed favorable treatment results. Also in an animal study, Karavana et al 2011, ${ }^{57}$ evaluated the therapeutic effect of topical benzydamine hydrochloride gel on oral ulcerations. They found that Bnz-HCL gel acts as protective coverage for the ulcers showing rapid decrease in their size and causing enhancement in healing rate.

Symptomatic oral lichen planus as a long term disease characterized by recurrent periods of remission and exacerbation which requires a safe, cheap and efficient pain relief therapy. ${ }^{58}$ The use of systemic steroids may cause relief of pain and resolution of the lesion. However, adverse effects are common even in short-term courses. At the same time prolonged use of systemic NSAIDs to decrease pain sensation is accompanied with other complications. ${ }^{59,60}$

\section{CONCLUSION}

Benzydamine hydrochloride gel is considered a simple, safe, well tolerated and effective method to reduce the severity of symptomatic oral lichen planus. It could be a good candidate for topical application in conjunction with intra-lesion corticosteroid therapy.

\section{REFERENCES}

1. Thongprasom K, Dhanuthai K. Steroids in the treatment of lichen planus: a review. Journal of Oral Science. 2008; 50(4): 377-385.

2. Mutafchieva MZ, Draganova-Filipova MN, Zagorchev PI, Tomov GT. Oral Lichen Planus - Known and Unknown: a Review. 2018;60(4): 528-535.

3. Mollaoglu N. Oral lichen planus: a review. Brit J Oral Maxillofacial Surg. 2000; 38(4): 370-7.

4. Gorouhi f, Davari P, Fazel N. Cutaneous and mucosal lichen planus: a comprehensive review of clinical subtypes, risk factors, diagnosis and prognosis. The Scientific World
Journal. 2014; Article ID 742826, 22 pages.

5. Cheng YSL, Gould A, Kurago Z, Fantasia J, Muller S. Diagnosis of oral lichen planus: a position paper of the American Academy of Oral and Maxillofacial Pathology. Oral Surgery, Oral Medicine, Oral Pathology and Oral Radiology. 2016; 122(3): 332-354.

6. Eisen D. The therapy of oral lichen planus. Crit Rev Oral Biol Med. 1993; 4: 141-158.

7. Silverman SJ, Bahl S. Oral lichen planus update: clinical characteristics, treatment responses, and malignant transformation. Am J Dent. 1997;10(6): 259-63.

8. Barnard NA, Scully C, Eveson JW, Cunningham S, Porter SR. Oral cancer development in patients with oral lichen planus. J Oral Pathol Med. 1993; 22 (9): 421-4.

9. Silverman S. Oral lichen planus: a potentially premalignant lesion. J Oral Maxillofacial Surg. 2000; 58(11): 1286-8.

10. Drangsholt M, Truelove EL, Morton TH, Epstein JB. A man with a thirty-year history of oral lesions. J Evid Base Pract. 2001; 1(2): 123-35.

11. Roopashree MR, Gondhalekar RV, Shashikanth MC, George J, Thippeswamy SH, Shukla A. Pathogenesis of oral lichen planus - a review. 2010; 39:729-734.

12. Scully C, Beyli M, Ferreiro MC, et al. Update on oral lichen planus: etiopathogenesis and management. Crit Rev Oral Biol Med. 1998; 9: 86-122.

13. Sugerman PB, Savage NW, Walsh LJ, et al. The pathogenesis of oral lichen planus. Crit Rev Oral Biol Med. 2002; 13: 350-65.

14. Ismail SB, Kumar SKS, Zain RB. Oral lichen planus and Lichenoid reactions; etiopathogenesis, diagnosis, management and malignant transformation. J Oral Sci. 2007; 49: 89-106.

15. Lodi G, Scully C, Carozzo M, et al. Current controversies in oral lichen planus: report on an international consensus meeting. Part 1. Viral infections and etiopathogenesis. 2005; 100: 40-51.

16. Zhou XJ, Sugarman PB, Savage NW, et al. Intra-epithelial CD8+ T cells and basement membrane disruption in oral lichen planus. J Oral Pathol Med. 2002; 31: 23-7.

17, Chainani-Wu N, Silverman SJ, Lozada NF, Mayer P, Watson JJ. Oral lichen planus: patient profile, disease progression and treatment responses. J Am Dent Assoc. 2001; 132: 901-9. 
18. Lodi G, Scully C, Carozzo M, et al. Current controversies in orallichen planus: report on an international consensus meeting. Part 1. Viral infection and etiopathogenesis. Triple O. 2005; 100: 40-51.

19. Zhao ZZ, Savage NW, Pujic Z, Walsh LJ. Immunohistochemical localization of mast cells and mast cell-nerve interactions in oral lichen planus. Oral Dis. 1997; 3:71-76.

20. Zhao ZZ, Sugerman PB, Zhou XJ, Walsh LJ, Savage NW. Mast cell degranulation and the role of T cell RANTES in oral lichen planus. Oral Dis. 2001; 7: 246-251.

21. Klein LM, Lavker RM, Matis WL, Murphy GF. Degranulation of human mast cells induces an endothelial antigen central to leukocyte adhesion. Proc Natl Acad Sci USA. 1989; 86: 8972-8976.

22. Walsh LJ, Trinchieri G, Waldorf HA, Whitaker D, Murphy GF. Human dermal mast cells contain and release tumor necrosis factor $\alpha$, which induces endothelial leukocyte adhesion molecule 1. Proc Natl Acad Sci USA. 1991; 88: 4220-4224.

23. Walton LJ, Thornhill MH, Farthing PM. VCAM-1and ICAM-1 are expressed by Langerhans cells, macrophages and endothelial cells in oral lichen planus. J Oral Pathol Med. 1994; 23: 262-268.

24.Gearing AJ, Beckett P, Christodoulou M, Churchill M, Clements J, Davidson AH, et al. Processing of tumour necrosis factor-alpha precursor by metalloproteinases. Nature. 1994; 370: 555-557.

25. McGeehan GM, Becherer JD, Bast RC Jr, Boyer CM, Champion B, Connolly KM, et al. Regulation of tumour necrosis factor-alpha processing by a metalloproteinase inhibitor. Nature. 1994; 370: 558-561.

26. Black RA, Rauch CT, Kozlosky CJ, Peschon JJ, Slack JL, Wolfson MF, et al. A metalloproteinase disintegrin that releases tumour-necrosis factor-alpha from cells. Nature. 1997; 385: 729-733.

27. Moss ML, Jin SL Milla ME, Bickett DM, Burkhart W, Carter HL, et al. Cloning of a disintegrin metalloproteinase that processes precursor tumour-necrosis factor-alpha. Nature. 1997; 385: 733-736.

28. Lavanya M, Jayanthi P, Rao U, Ranganathan K. Oral lichen planus: an update pathogenesis and treatment. Journal of Oral and Maxillofacial Pathology, 2011; 15(2): 127-132.
29. Edwards PC, Kelsch R. Oral lichen planus: clinical presentation and management. J Can Dent Assoc. 2002; 68 (8): 494-9.

30. Vente C, Reich K, Rupprecht R, Neumann C. Erosive mucosal lichen planus: response to topical treatment with tacrolimus. Br J Dermatol. 1999; 140 (2): 338-42.

31. Lundquist G, Forsgren H, Gajecki M, Emtestam L. Photochemotherapy of oral lichen planus: a controlled study. Oral Surg Oral Med Oral Pathol Oral Radiol Endod. 1995; 79(5): 554-8.

32. Xia J, Li C, Hong Y, Yang L, Huang Y, Cheng B. Short-term clinical evaluation of intralesional triamcinolone acetonide injection for ulcerative oral lichen planus. J Oral Pathol Med. 2006; 35:327-331.

33. Vincent SD. Diagnosing and managing oral lichen planus. JADA. 1991; 122(6): 93-6.

34. Lee YC, Lee JS, Jung AR, Park JM, Eun YG. Factors affecting the results of intralesional corticosteroid injection in patients with oral lichen planus. Clinical and Experimental Otorhinolaryngology. 2018; 11(3): 205-209.

35. Setterfield J, Black M, Challacombe S. The management of oral lichen planus. Clinical and Experimental Dermatology. 2000; 25: 176-182.

36. Sahebjamee M, Arbabi-Kalati F. Managenent of oral lichen planus. Arch Iranian Med. 2005;8(4): 252-256.

37. Sharma D, Sharma A, Garg R. Preparation, Physicochemical Evaluation and Characterization of Mucoadhesive Buccal Gels Impregnated with Benzydamine Hydrochloride for the Effective Treatment of Aphthous Stomatitis: Effect of Different Grades of HPMC Polymer on In vitro and Ex vivo Performance. Drug delivery letters. 2019; 9: 2210-3031.

38. Kerr D, Millard H. Oral diagnosis, second edition. C.V. Mosby Company, Saint Louis; Pp. 17, 1965.

39. Eisenberg E: Oral lichen planus: a benign lesion. J Oral Maxillofac Surg; 58: 1278-1285, 2000.

40. Hjerrnstad M.J., et al. Studies comparing numerical rating scales, verbal rating scales, and visual analog scales for assessment of pain intensity in adults: a systematic literature review. J Pain Symptom Manage; 41(6):1073-1093,2011.

41. Sadek HS. A clinical study of benzydamine hydrochloride mouth rinse as an adjunctive therapy for pain relief in the management of symptomatic oral lichen planus. Egyptian Dental Journal. 2013; 59: 4521-4529. 
42. Sironi M, Milanese C, Vecchi A, Polenzani L, Guglielmotti A, ColettaI, Landolfi C, Soldo L, Mantovani A, PinzaM. Benzydamine inhibits the release of tumor necrosis factoralpha and monocyte chemotactic protein- 1 by Candida albicans-stimulated human peripheral blood cells. Int J Clin Lab Res. 1997; 27: 118-122.

43. Carlucci G, Piera Iuliani P, Federico L. Simultaneous determination of benzydamine hydrochloride and five impurities in an oral collutory as a pharmaceutical formulation by high-performance liquid chromatography. J of Chromatographic Science. 2010; 48: 854-859.

44. Van Zyl A, Van Heerden W: Mouthwash: A review for South African health care workers. SAFam Pract. 2010; 52(2): 121-127.

45. Farah C, Mcilntosh L, McCullough M: Mouthwashes. Australian Prescriber. 2009; 32: 162-164.

46. Epstein JB, Silverman S, Paggiarino JR, Crockett DA, Schubert S, Senzer MM, Lockhart NN, Leveque DEFG. Benzydamine HCL for prophylaxis of radiation induced oral mucositis: results from a multicenter, randomized, double-blind, placebo-controlled clinical trial. Cancer. 2001; 92: 875-885.

47. Wiseman M: The treatment of oral problems in the palliative patient. J Can Dent Assoc. 2006; 72(5): 453-458.

48. Ludhwani S: Oral mucositis-management protocol by oral physician. International dental journal of student's research. 2012; 1(2): 6-12.

49. Pharmaceutical Substances-syntheses, patents, applications, A. Kleemann, J. Engel, third ed., Thieme.

50. Bickel MH, Weder HJ. Buccal absorption and other properties of pharmacokinetic importance of imipramine and its metabolites. J Pharmacol. 1969; 21: 160-168.

51. Baldock GA, Brodie RR, Chasseaud LF, Taylor T, Walmsley LM, Catanese B. Pharmacokinetics of benzydamine after intravenous, oral and topical dose to human subjects. Biopharm Drug Dispos. 1991; 12: 481-492.

52. Tas C, Ozkan Y, Savaser A, Baykara T. In vitro release studies of chlorpheniramine maleate from gels prepared by different cellulose derivatives. II Farmaco. 2003; 58: 605-611.

53. Pamela JH, Joel BE, Georgia RS. Oral and dental management related to radiation therapy for head and neck cancer. J Can Dent Assoc. 2003; 69(9): 585-90.

54. Schonemann NK, Van der Burght M, Arendt-Nielsen L. Onset and duration of hypoalgesia of lidocaine spray applied to oral mucosa- a dose response study. Acta Anaesthesiol Scand. 1992; 36: 733-5.

55. Rhen T, Cidlowski J: Anti-inflammatory action of Glucocorticoids- New Mechanisms for old drugs. New England of Medicine. 2005; 353: 1711-1723.

56. Karavana SY, Guneri P, Ertan G. Benzydamine hydrochloride buccal bioadhesive gels designed for oral ulcers: preparation, rheological, textural, mucoadhesive and release properties. Pharm Dev Technol. 2009; 14(6): 623-31.

57. Karavana SY, Sezer B, Guneri P, Veral A, Boyacioglu H, Ertan G, Epstein JB. Efficacy of topical benzydamine hydrochloride gel on oral mucosal ulcers: an in vivo animal study. Int. J. Oral Maxillofac. Surg. 2011; 40: 973-978.

58. Farhi D, Dupin N. Pathophysiology, etiologic factors, and clinical management of oral lichen planus, part I: facts and controversies. Clinics in Dermatology. 2010; 28: 100-108.

59. Lozada F, Silverman S, Migliorati C. Adverse side effects associated with prednisone in the treatment of patients with oral inflammatory ulcerative disease. J Am Dent Assoc. 1984; 1091: 269-270.

60. Dugowson C, Gnanashanmugam P. Non steroidal antiinflammatory drugs. Physical medicine and rehabilitation clinics of north America. 2006; 17: 347-354. 